\title{
Relative quantification of proteasome activity by activity-based protein profiling and LC-MS/MS
}

\author{
Nan Li, Chi-Lin Kuo, Guillem Paniagua, Hans van den Elst, Martijn Verdoes, Lianne I Willems, \\ Wouter A van der Linden, Mark Ruben, Eric van Genderen, Jacob Gubbens, Gilles P van Wezel, \\ Herman S Overkleeft \& Bogdan I Florea
}

Gorlaeus Laboratories, Leiden Institute of Chemistry and Netherlands Proteomics Centre, Leiden, The Netherlands. Correspondence should be addressed to B.I.F. (b.florea@chem.leidenuniv.nl)

Published online 23 May 2013; doi:10.1038/nprot.2013.065

\begin{abstract}
Activity-based protein profiling (ABPP) is a functional proteomics technique for directly monitoring the expression of active enzymes in cell extracts and living cells. The technique relies on irreversible inhibitors equipped with reactive groups (warheads) that covalently attach to the active site of enzymes and fluorescent or affinity tags for imaging and purification purposes, respectively. Here, a high-throughput and robust protocol for high-resolution quantitative activity-based proteasome profiling is described. We use both panreactive and subunit-specific fluorescent activity-based probes (ABPs) to quantify the proteasome activity in living cells, in the presence or absence of the potent proteasome inhibitor bortezomib. Active proteasome subunits from cell lysates are affinity-purified via a biotinylated ABP. Purification from live cells involves a two-step ABP approach using a reagent with a cell-permeable azide-warhead and postlysis installation of biotin. By means of liquid chromatography-mass spectrometry (LC-MS)-based proteomics, we can accurately identify the enriched proteins and the active site peptides of the enzymes, and relatively quantify all the proteasome activities in one experiment. The fluorescence ABPP protocols takes 2-3 d, and approximately $8-10 \mathrm{~d}$ are needed to complete the entire protocol.
\end{abstract}

\section{INTRODUCTION}

\section{Focusing on proteasome activities}

The proteasome is an evolutionarily conserved proteolytic complex that is responsible for the degradation of most proteins in eukaryotic cells ranging from yeast to human. It is essential for protein homeostasis and production of major histocompatibility complex (MHC) class I restricted epitopes. Protein degradation is necessary for the turnover of damaged or misfolded proteins and regulation of biochemical pathways by lowering enzyme activity or messenger concentration. Obviously, the proteasome is a central protease in various cellular processes, including transcription, translation, DNA repair, cell division and antigen presentation $^{1,2}$. In the past decade, the proteasome became an attractive clinical target after the approval of the proteasome inhibitor bortezomib (Velcade) by the US Food and Drug Administration for the treatment of multiple myeloma ${ }^{3}$. Encouraged by the clinical success of bortezomib, a series of new-generation proteasome inhibitors are being investigated as therapeutics of various diseases; thus, both (pre)clinical and fundamental knowledge of the activity of proteasomes is required.

The challenge of determining proteasome activity by a robust and high-throughput method is substantial. The proteasome is not a single protease, but a multisubunit protease cluster that, in eukaryotes, contains active subunits with different cleavage preferences. Mammalian 30 S proteasomes contain the catalytic 20S barrel-shaped core particle (CP) capped on both sides by 195 regulatory particles (Fig. 1). The 20S CP consists of four heptameric rings assembled from $\alpha$ - or $\beta$-subunits $\left(\alpha_{1-7}, \beta_{1-7}, \beta_{1-7}, \alpha_{1-7}\right)$ and harbors three different peptidase activities on each $\beta$-ring ${ }^{4,5}$. Crystallographic and substrate specificity studies ${ }^{6}$ show that the active site pockets of the $\beta 5$ subunits can accommodate and cut at the $\mathrm{C}$ terminus of bulky, hydrophobic amino acid residues in a manner that resembles chymotrypsin activity. $\beta 2$ subunits prefer cleaving after basic residues and are referred to as bearing 'trypsinlike' activities, whereas $\beta 1$ cuts after acidic residues and is known to have 'caspase-like' activity.

This constitutive $20 \mathrm{~S}$ proteasome CP is present in all eukaryotic cells. In immunocompetent tissues, three additional catalytically active $\beta$-subunits are expressed: $\beta$ 1i (low-molecular-weight protein-2, LMP2), $\beta 2 \mathrm{i}$ (multicatalytic endopeptidase complexlike-1, MECL1) and $\beta 5 \mathrm{i}\left(\right.$ LMP7) ${ }^{2}$. The immuno- $\beta$-subunits show comparable substrate cleavage preference, share around 50\% protein sequence identity and have different functional roles compared with the constitutive $\beta 1, \beta 2$ and $\beta 5$ subunits when replacing them in newly assembled $20 \mathrm{~S} \mathrm{CP}$, yielding the so-called immunoproteasomes ${ }^{1}$. Recently, a $\beta 5$ t subunit was identified that is exclusively expressed in cortical thymus epithelial cells, in which it is incorporated in immunoproteasomes instead of $\beta 5 \mathrm{i}$, yielding the thymo-proteasome ${ }^{7}$. Despite this diversity, the activity of the $\beta$-subunits is conveyed by the same mechanism of nucleophilic attack of the N-terminal threonine (Thr1) $\gamma$-hydroxyl on the peptide backbone ${ }^{8}$.

A commonly used technique to determine the proteasome activity is by means of fluorogenic substrates. Short peptides optically quench the aminocoumarin at their $\mathrm{C}$ termini, which upon cleavage by the proteasome is released and starts to fluoresce in solution ${ }^{9}$. Excellent subunit-specific fluorogenic substrates for each of the three constitutive $\beta$-subunit activities are commercially available; however, these substrates cannot discriminate between constitutive and immunoproteasome activities when present in the same cellular system. This problem is encountered during immunological studies of antigen presentation or (pre)clinical research in immune cells, such as leukemia and myeloma cells. 
a

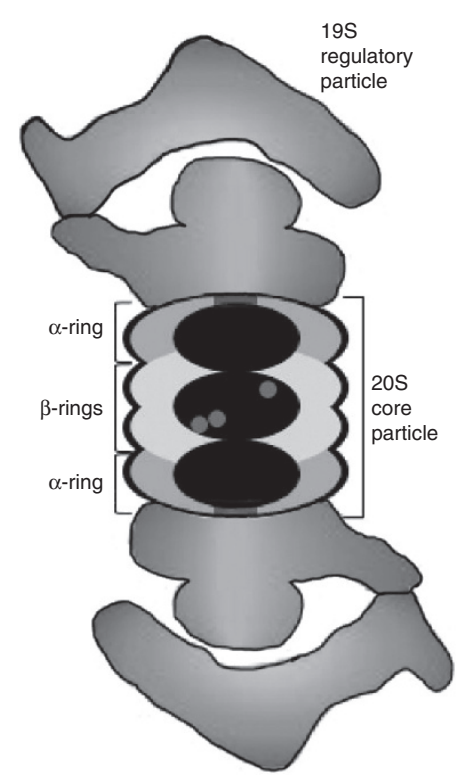

b

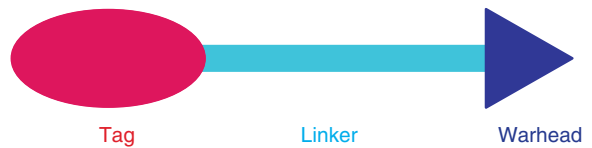

C

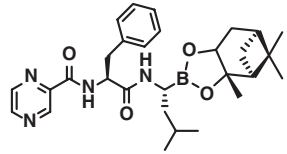

Bortezomib boric ester

d Affinity purification tools

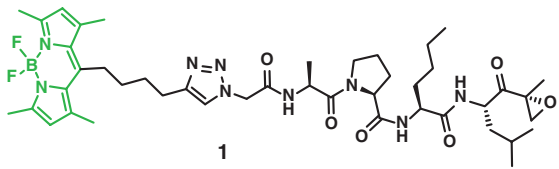<smiles>CCC(C)C(NC(=O)CCCCC1SCC2NC(=O)NC21)C(=O)NC(C(=O)NC(C(=O)NC1CC(C)C2OC2(C)C1=O)C(C)O)C(C)CC</smiles>

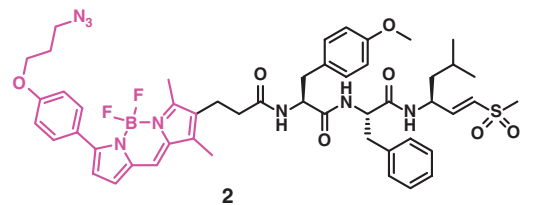

2

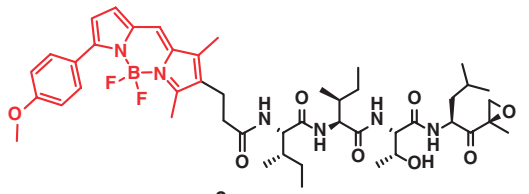

Figure 1 | Proteasome ABPP. (a) Model of the 30 S proteasome, in which active $\beta$-subunits are represented by gray spheres. (b) Schematics of a typical activity-based probe. (c) The proteasome inhibitor (bortezomib boric ester). (d) Activity-based proteasome profiling toolbox, LW124 (1) is a $\beta 1 / \beta 1$ i-specific probe, MVB127 (2) is a $\beta 5 / \beta 5 i$-specific probe, MVB003 (3) is a pan-reactive probe, Biotin-Epoxomicin (4) is a pan-reactive probe, $\mathrm{N}_{3}$-epoxomicin (5) is a two-step pan-reactive probe and Biotin-Phosphine (6) is a bio-orthogonal ligation compound for installing a biotin tag. Synthesis of the compounds is described in refs. 17-18,21-23.

\section{ABPP}

ABPP is a chemical proteomics technology that allows capturing, visualization, identification and quantification of the target enzymatic activities either in a test tube or in living systems ${ }^{10}$. It requires no protein purification step or specific labeled substrates, and it enables simultaneous labeling of multiple activities, providing a robust and high-throughput platform to observe the activity of the target enzyme (family). In ABPP workflows, organic compounds are used, i.e., the so-called ABPs, which are mechanism-based covalent and irreversible inhibitors of the target enzymes, equipped with a reporter group. A typical ABP consists of three parts: a reactive group (electrophilic trap or warhead) that targets the catalytic site of the enzyme; a spacer (linker) that serves as the recognition element for the enzyme-binding pockets; and a reporter group (tag) for detection (Fig. 1b).

Application of ABPP to proteasome activity assays embraces a rich history, from the early reports of natural products-inspired tritium-labeled lactacystin ${ }^{11}$ and biotin-labeled epoxomicin ${ }^{12}$ to more rational-design synthetic probes such as the ${ }^{125}$ I-labeled nitrophenol derivative of peptide vinyl sulfone $\mathrm{L}_{3} \mathrm{VS}$ (125I-NIP$\left.\mathrm{L}_{3} \mathrm{VS}\right)^{13}$ and the commercially available $\mathrm{N}$-terminal extended AdaAhx ${ }_{3} \mathrm{~L}_{3}$ VS inhibitor and its biotinylated AdaK(bio)Ahx ${ }_{3} \mathrm{~L}_{3} \mathrm{VS}$ derivative ${ }^{14}$. Advances in fluorescence detection methods allowed the development of fluorescent probes to replace the radioactivity-based probes, which are more technically challenging to handle. Berkers et al. ${ }^{15}$ synthesized DansylAhx ${ }_{3} \mathrm{~L}_{3} \mathrm{VS}$, which could be used for dual readout both by (weak) dansyl fluorescence or by western blotting with antibodies against dansyl. The bright, pan-reactive MV151 (ref. 16) and Bodipy-TMR-epoxomicin (MVB003, probe 3$)^{17}$ probes were followed by subunit-specific probes for the $\beta 5$ and $\beta 1$ activities $^{18}$, and several generations of ABPs equipped with different warheads, linkers and tags have been developed in our laboratory. For low-tech but high-throughput detection and quantification, DansylAhx ${ }_{3} \mathrm{~L}_{3}$ VS was used to determine proteasome activity in hematologic malignancies ${ }^{19}$, MV151 was instrumental to determine the proteasome activity in bortezomib-adapted cells ${ }^{20}$ and MVB003 highlighted the $\beta 5 t$ activity ${ }^{17}$.

MVB003 contains the epoxomicin sequence (Ile-Ile-Thr) and electrophilic trap (Leu-epoxyketone), which make the compound pan-reactive to all active proteasome subunits; it binds covalently, essentially labeling them with a fluorescent tag, and after SDSPAGE separation and fluorescence scanning of the wet gel slab, a characteristic banding pattern appears (Fig. 2, MCF7 cells), in which the $\beta 2$ subunit runs higher than the doublet consisting of the $\beta 1$ and $\beta 5$ subunits. However, a general shortcoming of the panreactive probes is that, in the case of immunoproteasomes, the molecular weight and thus the electrophoretic gel shift of the $\beta 1 / \beta 1 \mathrm{i} / \beta 5 / \beta 5 \mathrm{i}$ subunits on a standard 8 -cm-tall $1 \mathrm{D}$ SDS-PAGE gel is limited; thus, their signals overlap, show poor resolution and cannot be individually quantified (Fig. 2, AMO1 cells). To overcome this problem, we have initiated a rational design and screening program ${ }^{18}$ to synthesize the $\beta 1 / \beta 1$ i-selective sequence (Ala-Pro-dNorLeu) equipped with a Leu-epoxyketone warhead for probe 1 and the $\beta 5 / \beta 5$ i-selective sequence (metTyr-Phe) with the Leu-vinylsulfone electrophilic trap for probe 2 . The subunit-specific probes $\mathbf{1}$ and $\mathbf{2}$ (Fig. 1d) proved to be a remarkable technical improvement that could solve this problem, allowing for the separation of $\beta 1$ i from $\beta 1$ and $\beta 5$ i from $\beta 5$ on SDS-PAGE with superior resolution, although the $\beta$-subunits have a difference of 
PROTOCOL

Figure 2 | Results of fluorescence-based quantitative proteasome ABPP. Results are shown in adherent-growing breast carcinoma cell line MCF7 expressing constitutive proteasome, and in suspension-growing cells AM01 expressing both constitutive proteasomes and immunoproteasomes incubated with increasing bortezomib concentrations. Top, the global proteasome assay with MVB003 (3) used for quantification of $\beta 2 / \beta 2 i$ activities. Middle, $\beta 1 / \beta 1$ i quantification with LW124 (1). Bottom, $\beta 5 / \beta 5 i$ quantification with MVB127 (2). The graphs show the proteasome activity, quantified from the gel bands, after treatment with increasing concentrations of bortezomib.

$\sim 500 \mathrm{Da}$ in molecular weight. Furthermore, relative quantification of an individual activity between different samples can be done by fluorescence signal analysis in gel. The schematics of this experiment are shown in Figure 3 (lower route).

Alternatively, proteasome ABPP can be performed with direct onestep biotinylated ABP (4) or two-step bioorthogonal tools ( 5 and 6) ${ }^{17,21}$. For one-step ABPP, proteasome active subunits in cell extracts are labeled with biotinylated probe $\mathbf{4}$, followed by affinity purification with streptavidin-coated paramagnetic beads. Because biotin hampers probe permeability in living cells, the two-step approach is used when the azide-equipped probe 5 labels the active proteasome in living cells, and after cell lysis the reporter or affinity tag of choice is installed via a bio-orthogonal reaction ${ }^{22,23}$. After the pull-down step, enriched proteins are identified by on-bead tryptic digestion and LC-MS-based proteomics analysis (Fig. 3, upper route). For relative quantification of proteasome activity, we have combined the stable isotope dimethyl labeling method ${ }^{24,25}$ with our affinity purification ABPP platform because it is a general labeling method that can be applied to peptide samples of various origins ranging from tissue cultures to biopsies taken from patients. After on-bead digestion, tryptic peptides were loaded on a C18 solid support on which both the di-methyl labeling and the desalting were performed, and after elution the samples were mixed and analyzed by LC-MS. The open-source MaxQuant software 26,27 was then used for peptide identification and quantification. In addition, active site peptides can also be analyzed by LC-MS after elution from the streptavidin beads.

Bortezomib shows much higher affinity for the $\beta 5 / \beta 5 \mathrm{i}$ and $\beta 1 / \beta 1 \mathrm{i}$ subunits because it is stabilized by hydrogen bonding in these active sites ${ }^{6}$, and we can accurately quantify the potency

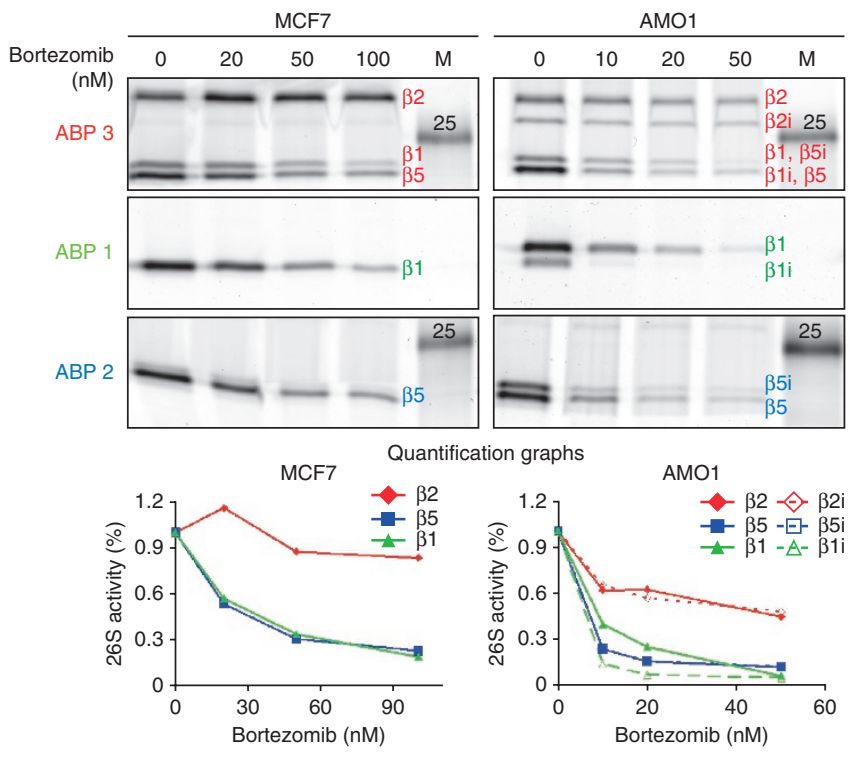

and the subunit specificity of bortezomib. This platform can find other applications, for instance in the screening for novel proteasome inhibitors. With this combination of methods and by using the MVB003 probe, we have demonstrated that the newly discovered $\beta 5$ t subunit, expressed only in the thymus, is indeed catalytically active ${ }^{17}$.

\section{Advantages and limitations with respect to other methods}

The study of the individual function of active $\beta$-subunits by genetic knockdown in yeast proved to be difficult because these subunits are essential for survival of the cell28; for this reason, chemical modulation and readout of activity is preferred. Compared with the popular method of proteasome activity determination by fluorogenic substrate assay, the ABPP method is high throughput (no need for protein purification), robust and simple (no specific substrates needed and little off-target labeling), of superior resolution (capability to distinguish constitutive and immunoactivities), and is compatible with living cells (good cell permeability shown by ABPs).

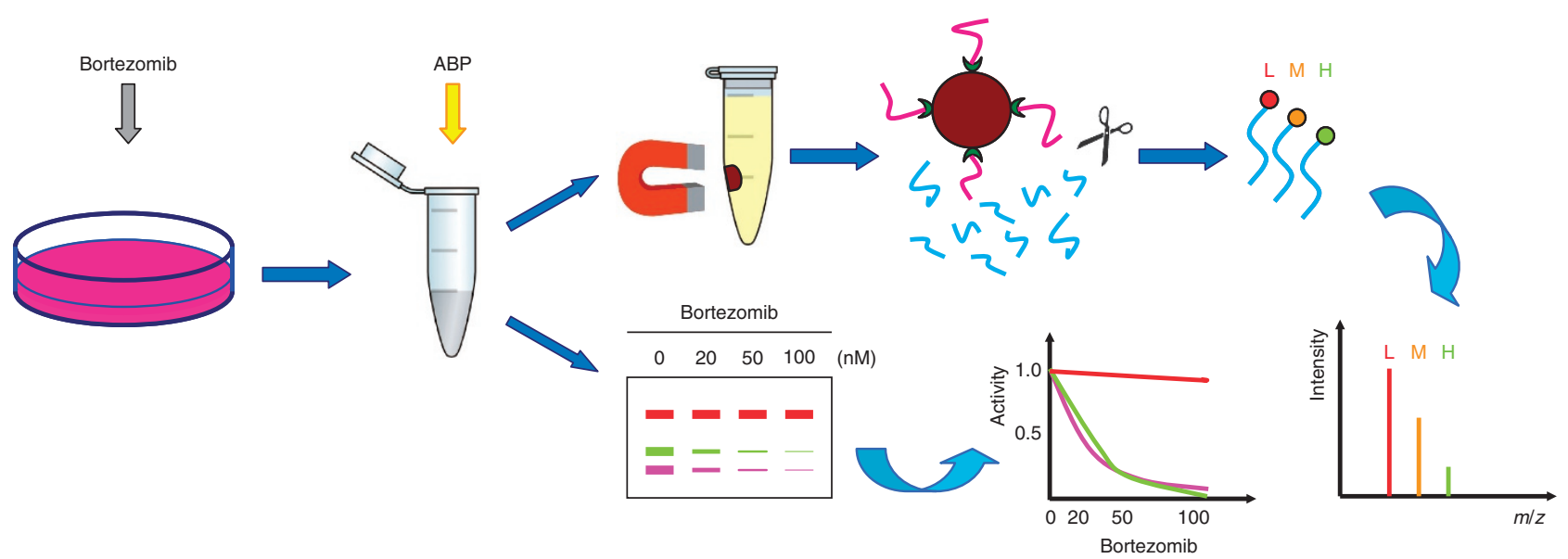

Figure 3 | Schematic overview of the quantitative activity-based proteasome profiling experiments. The upper pathway describes the one- or two-step affinity purification protocol using the biotin-streptavidin system, followed by stable isotope labeling, LC-MS-based proteomics analysis and quantification. Active site peptides (in pink) are analyzed after elution from the beads. The lower pathway shows the SDS-PAGE analysis and quantification of a competitive ABPP experiment. 
There are some drawbacks to the chemical and mechanismbased nature of the method. It is possible that the chemicals used as probes can also hit targets other than the proteasome, which might limit their use in living cells. Because the probes bind covalently to the catalytic sites, the enzymatic activity is consumed during the measurement, necessitating the analysis of time dependency when enzyme kinetics need to be assayed. For accurate kinetic measurements, it is necessary to determine enzyme activity by taking increasing concentrations of the probe and incubating them for increasing amounts of time. A rate constant $\left(k_{\text {obs }}\right)$ for each probe concentration is extracted from the semi-logarithmic plot of enzyme activity versus time, and it is plotted against the probe concentration to determine the affinity of the probe for the enzyme $\left(K_{i}\right.$ value). For an excellent review on this methodology, see Singh et al. ${ }^{29}$. However, these extensive studies are not necessary for global screens using a standard incubation time and probe concentration, which should make the inter-experiment results comparable. The ABPP assays presented here are not easily scalable to high-throughput 96-well format, and require relatively high $\left(5 \times 10^{6}\right.$ to $\left.10 \times 10^{6}\right)$ cell numbers. An ELISA-based, high-throughput method for the analysis and quantification of active site peptides of the proteasome $\beta$-subunits is described by Muchamuel et al. ${ }^{30}$.

Despite the few drawbacks, our ABPP platform seems to be a powerful method that facilitates quantitative comparison between different treatments, e.g., increasing concentrations of bortezomib. It allows the analysis of all proteasome activities in one experiment in living cells, can be used for the identification of the active site peptides and is applicable to clinical samples. Although we have described it here for the analysis of proteasome activity, this protocol can be used as a guideline for setting up comparable ABPP workflows ${ }^{10}$. Recently, we have adapted this method to determine the activity of the membrane-bound cerebrosidase GBA1 and GBA2 enzymes that are expressed at very low abundance $(1: 300,000)^{31}$. The fluorescent probes can also find applications in fluorescence microscopy and flow cytometry analysis, as exemplified by asymmetric T lymphocyte division caused by unequal proteasome segregation between daughter cells ${ }^{32}$. For background information on the use of click chemistry (TOP-ABPP) for performing two-step labeling and the use of the stable isotope in cell culture labeling (ABPP-SILAC) approach, we recommend reading the work from the Cravatt laboratory 33,34 . In the future, the proteasome will be an interesting target for rational drug design of novel antibiotics ${ }^{35}$, and the ABPP method might find application in this field. In this manuscript, we give a step-by-step description of a competitive ABPP protocol in which the $\beta$-subunit activity of the proteasome is determined in cells after treatment with bortezomib as well as in nontreated cells.

\section{Experimental design}

High-resolution fluorescence ABPP. This method can be easily implemented in any laboratory that has basic cell culture and protein analysis equipment. The method has been used successfully in many different mammalian cell culture systems ranging from immortal cell lines to primary cells and from adhering to suspension cultures. Typical applications are for drug discovery programs of novel proteasome inhibitors, determination of the effect of a drug on the proteasome activity, antibiotic discovery ${ }^{35}$ or basic understanding of proteasome biology in plants ${ }^{36}$. In this protocol, human and mouse cell lines are incubated with increasing concentrations of bortezomib, and the remaining activity of individual $\beta$-subunits of both the constitutive proteasome and the immunoproteasome in the respective cell lysates is determined. The advantage of postlysis ABPP is that the same lysate can be interrogated with different probes and compared. Alternatively, because probes 1, 2 and 3 are cell permeable, they can be added in parallel to cells after bortezomib treatment to study competition in the context of living cells. This assay can be performed in 6- or 12-well formats, but not in larger formats because protein isolation from small cell numbers would prove to be too difficult. The experiments should be performed at least in duplicate, and incubation with $0 \mathrm{nM}$ bortezomib serves as a positive control for the determination of the maximum probe-binding signal. Incubation with a potent and panreactive inhibitor to all proteasome $\beta$-subunits (e.g., $\mathrm{N}_{3}$-epoxomicin, 5) or boiling the cell lysate with $1 \%$ (wt/vol) SDS before labeling with the ABPs can serve as negative controls. Commercially available protease inhibitor cocktails are tolerated during lysis. We have tested the protease inhibitor cocktail tablets (Roche) and PMSF (Sigma) and found that they do not compete for the covalent binding between ABP and proteasome subunits (B.I.F., unpublished results).

For quantification purposes, it is important that the cell lysis buffer is compatible with the protein determination method used after cell lysis, as it can be sensitive to some detergents (SDS, Triton X-100) or reducing agents (e.g., DTT) that can skew the measured protein concentration. SDS-PAGE analysis is best performed in $12.5 \%$ (wt/vol) acrylamide gels, followed by imaging the ABP-labeled $\beta$-subunits simply by scanning on a fluorescence bed scanner. Active $\beta$-subunits of the constitutive proteasome show a typical banding pattern of $\beta 2$ above the $25-\mathrm{kDa}$ marker and $\beta 1$ and $\beta 5$ subunits as a doublet below the $25 \mathrm{kDa}$. Commercial dual or multicolor protein markers contain a red band at $25 \mathrm{kDa}$ that appears in the 'red' channel used for probes 2 and 3; however, up to a $40 \times$ dilution of the marker might be necessary to prevent signal saturation. Mixed proteasomes (constitutive proteasome and immunoproteasome) show an additional $\beta 2 \mathrm{i}$ band between the $\beta 2$ and $\beta 1$ band, and because the molecular weights of $\beta 1, \beta 1 i, \beta 5$ and $\beta 5 \mathrm{i}$ subunits are in close proximity, they are poorly separated on gel. However, high-resolution separation can be achieved by using the subunit-specific probes 1 for $\beta 1 \beta 1$ i and 2 for $\beta 5 \beta 5 i$, allowing for quantification of the individual band signals. Coomassie blue staining is a facile and reliable method to correct and normalize for pipetting errors, and it should be performed after the fluorescence scanning.

The outcome of a typical competitive ABPP experiment is that the signal of one or several $\beta$-subunit bands decreases with increasing competitor concentrations, which highlights the superior sensitivity and resolution of the ABPP method compared with fluorogenic assays because the detected signal provides both the identity and the intensity of the active $\beta$-subunit. By plotting the signal intensity against the concentration of the competitor compound, one can estimate the potency and selectivity of the competitor for the proteasome subunits.

When you are exploring organisms with poorly annotated genomes, ABPP can reveal the identity of the active proteasome genes, which is particularly interesting for profiling pathogenic 
organisms that cause disease in humans and animals. The ABPP method can be used with virtually all proteasome inhibitors, given that they display an interaction strong enough to outcompete the covalent ABP from binding. The method is also adaptable to organisms other than mammals; it works in all types of cell lysates. However, probe optimization and identification of gel bands by affinity purification and LC-MS-based proteomics is necessary for organisms that have cell walls or that show extensive efflux pump activities, including pathogens, yeasts and plants ${ }^{36}$.

Quantitative LC-MS-based ABPP. Protein identification by LC-MS is very sensitive to background pollutants such as keratins from dust, plasticizers from plastics or tubing and polymeric detergents (e.g., Triton, Tween). For this work, it is advisable to create a dedicated laboratory space with a laminar flow cabinet, dedicated pipette sets, tubes, tips and, importantly, dedicated solutions. Protect your work from dust and wear gloves during experiments; gloves should be rinsed regularly in order to avoid electrostatic dust accumulation. Keep organic solvents in glass containers and use chemically pure water ( $18 \mathrm{M} \Omega$ ) either freshly tapped from the deionizing apparatus or commercially available (e.g., Biosolve). Do not use autoclaved water because it is full of plasticizers or PEGs that pollute the LC-MS. The use of low-binding tips and tubes (e.g., Sarstedt, Eppendorf) is advisable to prevent the loss of proteins/peptides due to adsorption to plastics.

To determine the proteasome activity in living cells or cell lysates by LC-MS-based ABPP, it is necessary to first capture the active subunits by covalent binding to the $\mathrm{ABP}$, followed by affinity purification of the active subunits. ABPs equipped with a biotin tag are the most popular because they facilitate the use of robust biotin-streptavidin affinity purification workflows. However, the presence of biotin reduces the cell permeability of ABPs, making it unsuitable for use in living cells. A solution to this problem is presented in this protocol, in which epoxomicin equipped with an $\mathrm{N}$-terminal azide $\left(\mathrm{N}_{3}\right)$ ligation handle $(5)$ that retains perfect cell permeability was used to capture residual proteasome activity after bortezomib treatment in living cells; this was followed by postlysis introduction of biotin via a bio-orthogonal reaction with biotinphosphine (6) in the aqueous environment. We have explored several other bio-orthogonal ligation procedures such as the $\mathrm{Cu}^{+}$catalyzed Huisgen 1,3-dipolar cycloaddition (click chemistry) ${ }^{34}$ or copper-free approaches ${ }^{37}$, and we have empirically discovered that the azide-phosphine ligation pair under native (nondenaturing) conditions proved to be the most robust for the proteasome activity determination because the phosphine reagent is simply added to the lysate; there is no need for a catalyst, and we have experienced less protein precipitation ${ }^{37}$.

High concentrations of biotin-phosphine $(250 \mu \mathrm{M})$ and removal of this excess after the reaction by precipitating the proteins is necessary for the protocol. Protein precipitation with the chloroform/ methanol method ${ }^{38}$ has several advantages compared with acetone precipitation or size-exclusion cleanup: it is a rapid method (it takes only 10-15 min), it allows choice in partition of chemical impurities either to the aqueous or organic phase, it is adaptable for a wide range of protein concentrations from $10 \mu \mathrm{g}$ to several $\mathrm{mg}$ and the loss of material is low. A drawback of the method is that protein pellets should be dried no longer than $5 \mathrm{~min}$, and the use of $1-4 \%(\mathrm{wt} / \mathrm{vol})$ SDS-containing buffers is necessary for dissolving the proteins. SDS concentration needs to be decreased before the pull-down because it can interfere with, and lower, the biotin-streptavidin interaction. Several strategies can be adopted: dispersion of protein pellets in a small volume $(25 \mu \mathrm{l})$ of $2 \%$ (wt/vol) SDS buffer followed by stepwise addition of the buffer, increasing the volume of solvation but slowly diluting out the SDS to keep its solvation power, as described in this protocol; dissolving the pellet in a larger volume $(500 \mu \mathrm{l})$ of $2-4 \%$ (wt/vol) SDS, followed by dilution to $0.05-0.1 \%$ (wt/vol) SDS in several tens of milliliters of buffer; the use of a larger amount of beads ( $1 \mathrm{mg}$ or more); and increased pull-down time, such as overnight at $4{ }^{\circ} \mathrm{C}$, as described in Kallemeijn et al. ${ }^{31}$.

We have tested several sources and types of paramagnetic streptavidin-coated beads, and for this protocol monodisperse, high-binding capacity, $1-\mu \mathrm{m}$-diameter beads showed superior pull-down efficiency (B.I.F., unpublished results). The advantage of paramagnetic beads compared with agarose beads is the ease of liquid handling because the beads stick to the tube wall when a magnetic field is applied. The high binding affinity of biotin for streptavidin facilitates stringent washing that decreases protein background but cannot discriminate for endogenously biotinylated proteins. Elution of biotinylated proteins is not trivial, and two possibilities are presented: the first is elution by boiling SDS-PAGE sample buffer containing SDS under denaturing conditions and in the presence of an excess of free biotin to displace the bound proteins from the streptavidin matrix. A second option is on-bead digestion with trypsin for LC-MS proteomics analysis. Elution in sample buffer affords the possibility of SDS-PAGE analysis that can yield valuable information about protein molecular weight, and after in-gel tryptic digest ${ }^{39}$ protein identity can be determined by LC-MS analysis. For on-bead tryptic digestion, an estimation of the trypsin quantity should be made, as most protocols use a 1:100 ratio of trypsin: protein. We have shown by empirical evaluation that by starting with $1 \mathrm{mg}$ of protein and $500 \mu \mathrm{g}$ of beads, $500 \mathrm{ng}$ of trypsin yields reproducible results (B.I.F., unpublished results).

For the comparison of treated versus nontreated samples by relative quantification using LC-MS-based proteomics, we have chosen to introduce 'light', 'medium' and 'heavy' labels with stable isotope by reductive amination of primary amines at the $\mathrm{N}$ termini and $\varepsilon$-position of lysine residues using formaldehyde 24,25 . This robust technique, applicable to virtually all types of protein specimens ranging from clinical samples to cell culture lysates, has been adapted and optimized in this protocol for small protein amounts that are obtained after affinity purification, by using the stage-tip method ${ }^{40}$. Finally, after on-bead tryptic digestion, the active site peptides bound to the biotinylated probe can be eluted with acetonitrile/formic acid mixtures (containing free biotin) and can be used for unraveling the binding mechanism of the probe to the protein by MS/MS or MS/MS/MS analysis of the ion fragments. 


\section{MATERIALS}

\section{REAGENTS}

- $\triangle$ CRITICAL The chemical compounds from Figure 1 are available upon request; the primary papers that describe their synthesis are refs. 17,18,21,22.

- MCF7 (HTB-22) and EL4 (TIB-39) cells are commercially available from ATCC. See Box 1 for information regarding cell culture and protein extraction

- AMO-1 (ACC-538) was a kind gift from the Driessen laboratory ${ }^{19,20}$, and it is commercially available from the Leibniz Institute DSMZ-German Collection of Microorganisms and Cell Cultures. See Box $\mathbf{1}$ for information regarding cell culture and protein extraction

- ACN (acetonitrile; Sigma-Aldrich, cat. no. 14261)

- ATP (adenosine triphosphate; Sigma-Aldrich, cat. no. A2383)

- $\mathrm{NH}_{4} \mathrm{HCO}_{3}$ (ammonium bicarbonate; Sigma-Aldrich, cat. no. 09830)

- APS (ammonium persulfate; Sigma-Aldrich, cat. no. A3678)

- $\beta$-Mercaptoethanol ( $\beta$-ME; Sigma-Aldrich, cat. no. M3148)

- BSA (Sigma-Aldrich, cat. no. A7906)

- $\mathrm{CaCl}_{2}$ (calcium chloride; Sigma-Aldrich, cat. no. 223506)

- $\mathrm{CHCl}_{3}$ (chloroform; Sigma-Aldrich, cat. no. 650498)

- Colloidal blue staining kit (Invitrogen, cat. no. LC6025)

- Digitonin (Sigma-Aldrich, cat. no. D141)

- $\mathrm{Na}_{2} \mathrm{HPO}_{4}$ (disodium hydrogen phosphate; Sigma-Aldrich, cat. no. S3264)

- $\mathrm{KH}_{2} \mathrm{PO}_{4}$ (potassium phosphate monobasic; Sigma-Aldrich,

cat. no. P5655-500G)

- $\mathrm{K}_{2} \mathrm{HPO}_{4}$ (potassium phosphate dibasic; Sigma-Aldrich, cat. no. P2222-500G)

- DTT (dithiothreitol; Sigma-Aldrich, cat. no. 43815)

- DMSO (dimethyl sulfoxide; Sigma-Aldrich, cat. no. D8418)

- ECL Plus western blotting system (GE Healthcare, cat. no. RPN2132)

- $\mathrm{CH}_{2} \mathrm{O}$ (light formaldehyde; Sigma-Aldrich, cat. no. F8775)

- $\mathrm{CD}_{2} \mathrm{O}$ (intermediate formaldehyde; Sigma-Aldrich, cat. no. 492620)

- ${ }^{13} \mathrm{CD}_{2} \mathrm{O}$ (heavy formaldehyde; Sigma-Aldrich, cat. no. 596388)

I CAUTION Work with formaldehyde in a fume hood because the solutions and vapors are toxic.

- FA (formic acid; Sigma-Aldrich, cat. no. F0507)

- Glycerol (Sigma-Aldrich, cat. no. G5516)

- Glycine (Sigma-Aldrich, cat. no. G8898)

- $\mathrm{HCl}$ (hydrochloric acid, Sigma-Aldrich, cat. no. 84415)

- IAA (iodoacetamide; Sigma-Aldrich, cat. no. I1149)
- $\mathrm{MgCl}_{2}$ (magnesium chloride; Sigma-Aldrich, cat. no. M8266)

- Tergitol NP-40 (Sigma-Aldrich, cat. no. NP40)

- $\mathrm{KCl}$ (potassium chloride; Sigma-Aldrich, cat. no. P9541)

- Trypsin (Promega, cat. no. V5111)

- SDS (Sigma-Aldrich, cat. no. L4390)

- SilverQuest staining kit (Invitrogen, cat. no. LC6070)

- Bradford assay reagent (Bio-Rad, cat. no. 500-0205)

- $\mathrm{NaCl}$ (sodium chloride; Sigma-Aldrich, cat. no. S3014)

- $\mathrm{NaBH}_{3} \mathrm{CN}$ (sodium cyanoborohydride; Sigma-Aldrich, cat. no. 156159)

- $\mathrm{NaBD}_{3} \mathrm{CN}$ (sodium cyanoborodeuteride; Sigma-Aldrich, cat. no. 190020)

- $\mathrm{NaH}_{2} \mathrm{PO}_{4}$ (sodium dihydrogen phosphate; Sigma-Aldrich, cat. no. S3139)

- Sucrose (Sigma-Aldrich, cat. no. 84097)

- TEMED $\left(N, N, N^{\prime}, N^{\prime}\right.$-tetramethylethylenediamine; Sigma-Aldrich, cat. no. T9281)

- Tris (Sigma-Aldrich, cat. no. T6066)

- Tween-20 (Sigma-Aldrich, cat. no. P9416)

- Urea (Sigma-Aldrich, cat. no. U5378)

- Biotin (Sigma-Aldrich, cat. no. B4639)

- Dynabeads MyOne Streptavidin C1 (Invitrogen, cat. no. 650-01)

- EDTA (ethylenediaminetetraacetic acid; Sigma-Aldrich, cat. no. E6758)

- Ethanol (VWR, cat. no. 20816.298)

- Methanol (VWR, cat. no. 83638.290)

- Bortezomib ester (Fig. 1; Selleck Chemicals, cat. no. S1013)

- LW124 (1, Fig. 1) ${ }^{18}$

- MVB127 (2, Fig. 1)18

- MVB003 (3, Fig. 1) 17

- Biotin-epoxomicin (4, Fig. 1$)^{17}$

- $\mathrm{N}_{3}$-epoxomicin (5, Fig. 1$)^{17}$

- Biotin-phosphine (6, Fig. 1) 21,22

- DMEM (Dulbecco's modified Eagle's medium; PAA, cat. no. E15-883)

- RPMI-1640 (PAA, E15-041)

- FCS (PAA, cat. no. A15-104)

- Stable L-glutamine (PAA, cat. no. M11-006)

- Penicillin (Duchefa Biochemie, cat. no. P0142.0100)

- Streptomycin (Duchefa Biochemie, cat. no. S0148.0100)

- BPB (bromophenol blue; Sigma-Aldrich, cat. no. B0126-25G)

- Dual-color marker (Precision Plus protein standards; Bio-Rad, cat. no. 161-0374)

- Milli-Q water

\section{Box 1 | Cell culture and protein extraction TIMING $1 \mathrm{~d}$}

In this study, we have used adherent- and suspension-growing cells from humans and mice to show that the activity-based protein profiling method can be used in virtually all in vitro-cultured mammalian cell types including primary cells. In (micro)organisms bearing a cell wall (e.g., yeast, plants), the method works well in cell lysates, but it should be optimized (mostly by using higher probe concentrations) for living cells.

\section{PROCEDURE}

1. Cell culture. MCF7 (human breast carcinoma) and EL4 (murine T lymphocyte) cells are grown in DMEM with $10 \%$ (vol/vol) FCS, $0.1 \mathrm{mg} \mathrm{ml}-1$ penicillin and $0.1 \mathrm{mg} \mathrm{ml}^{-1}$ streptomycin in a $37{ }^{\circ} \mathrm{C}, 7 \% \mathrm{CO}_{2}$ incubator. AMO1 (plasmacytoma) cells are grown in RPMI-1640 medium with $10 \%$ (vol/vol) FCS, $0.1 \mathrm{mg} \mathrm{ml}^{-1}$ penicillin, $0.1 \mathrm{mg} \mathrm{ml}^{-1}$ streptomycin and $2 \mathrm{mM}$ stable L-glutamine in a $37{ }^{\circ} \mathrm{C}$, $5 \% \mathrm{CO}_{2}$ incubator.

2. Harvesting. Collect MCF7 cells by scraping them in cold PBS. Collect EL4 and AM01 cells by centrifugation directly at $200 \mathrm{~g}$ at room temperature for $5 \mathrm{~min}$. Wash the cells with ice-cold PBS three times to remove serum and free inhibitor molecules.

PAUSE POINT The cells can be stored in a freezer at $-80^{\circ} \mathrm{C}$ for a couple of months.

3. Protein extraction. Thaw the cell pellets from $-80^{\circ} \mathrm{C}$ on ice, add 4 volumes of lysis buffer to the cell pellet and leave it on ice for 15-30 min. Sonicate the cells on ice three times, for $10 \mathrm{~s}$ each time, at $12 \mathrm{~W}$, with a 5-s pulse/pause. Centrifuge the lysate for 10 min at top speed ( $13 \mathrm{~K} \mathrm{r.p.m.)}$ at $4{ }^{\circ} \mathrm{C}$.

I CAUTION Check by eye whether the supernatant is clearly transparent.

4. Lysate storage. Transfer the supernatant to new Eppendorf tubes. Determine the protein concentration by using the Bradford protein assay, and then freeze the lysate at $-80^{\circ} \mathrm{C}$ for future use.

! CAUTION Divide the lysate into small portions to avoid freezing and thawing multiple times.

PAUSE POINT The lysate can be kept at $-80{ }^{\circ} \mathrm{C}$ for a couple of weeks. 


\section{EQUIPMENT}

Cell culture

- Galaxy 170 $\mathrm{CO}_{2}$ incubator (New Brunswick)

- Clean air cabinet (Thermo)

- Eppendorf centrifuge 5702 (Eppendorf, cat. no. 5702 000.019)

- Eppendorf centrifuge 5424 (Eppendorf, cat. no. 5424 000.410)

- Cell culture flasks (PAA, cat. nos. PAA70325X and PAA70375X)

- Cell culture dishes (PAA, cat. nos. PAA20035X, PAA20060X, PAA20101X and PAA20151X)

- Eppendorf pipettes (Eppendorf, cat. nos. 3120 000.011, 3120 000.038, 3120000.054 and 3120000.062 )

- Accu-jet pro pipette controller (BrandTech, cat. no. 2026330)

- Cell lifter (Corning, cat. no. 3008)

- Petri dish

- Pipette tips (Sarstedt, cat. nos. 70.1130, 70.760 .002 and 70.762)

- Refrigerator/freezer (Bosch)

- Serological pipettes (Sarstedt, cat. nos. 86.1252.025, 86.1253.025, 86.1254 .025 and 86.1685 .020$)$

- Water bath, $37^{\circ} \mathrm{C}$ (Grant)

Protein extraction

- Eppendorf cool centrifuge 5402 (Eppendorf)

- Vortex Genie 2 mixer (Scientific Industries, cat. no. SI-0256)

- Sonicator (Sonics, cat. no. VC 505)

- GENios plate reader (Tecan)

- Ice maker (Hoshizaki)

- Forma $-86^{\circ} \mathrm{C}$ ULT freezer (Thermo)

- Multichannel pipette, 10-100 $\mu \mathrm{l}$ (Eppendorf, cat. no. 3120 000.046)

• 96-well plates (Greiner Bio One, cat. no. 655101-ORT)

Affinity purification

- Thermomixer compact (Eppendorf)

- Test tube rotator (Labinco, cat. no. 29000)

- QBD2 metal heating block (Fisher, cat. no. BLD-560-020X)

- Bio-Rad mini protean 3 gel-running system (with power supply and blot transfer unit)

- SSM4 rocker (Stuart)

- DynaMag-2 (Invitrogen, cat. no. 123.21D)

- SpeedVac

Imaging

- Bio-Rad ChemDoc system (with GS-800 scanner)

- Typhoon 9400 scanner (GE Healthcare)

- ImageJ software

LC-MS system

- LTQ-Orbitrap mass spectrometer (Thermo-Fisher Scientific)

REAGENT SETUP

TBS, 10× Dissolve $12.1 \mathrm{~g}$ of Tris and $88 \mathrm{~g}$ of $\mathrm{NaCl}$ in $800 \mathrm{ml}$ of $\mathrm{H}_{2} \mathrm{O}$; next, adjust the $\mathrm{pH}$ to 7.5 , add $\mathrm{H}_{2} \mathrm{O}$ up to a final volume of 1 liter and filter-sterilize the solution. TBS can be stored at room temperature $\left(20^{\circ} \mathrm{C}\right)$ for several months.

TBST Dilute $100 \mathrm{ml}$ of $10 \times$ TBS to 1 liter in $\mathrm{H}_{2} \mathrm{O}$; add $1 \mathrm{ml}$ of Tween- 20 and mix the solution well. Prepare TBST freshly every week and keep it at room temperature.

PBS, 10× Dissolve $6.8 \mathrm{~g}$ of $\mathrm{KH}_{2} \mathrm{PO}_{4}$ in $50 \mathrm{ml}$ of $\mathrm{H}_{2} \mathrm{O}$ and $26.1 \mathrm{~g}$ of $\mathrm{K}_{2} \mathrm{HPO}_{4}$ in $150 \mathrm{ml}$ of $\mathrm{H}_{2} \mathrm{O}$; mix the solution, dilute it to $800 \mathrm{ml}$ and use it to dissolve $87.7 \mathrm{~g}$ of $\mathrm{NaCl}$. Adjust the $\mathrm{pH}$ to 7.6 , add $\mathrm{H}_{2} \mathrm{O}$ up to a final volume of 1 liter and filter-sterilize the solution. This solution can be stored for several months.

Lysis buffer Mix $50 \mathrm{mM}$ Tris-HCl, pH 7.5, $250 \mathrm{mM}$ sucrose, $5 \mathrm{mM} \mathrm{MgCl}_{2}$, $1 \mathrm{mM}$ DTT, $2 \mathrm{mM}$ ATP, $0.025 \%$ (wt/vol) digitonin and $0.2 \%$ (vol $/ \mathrm{vol}$ ) NP-40. Freshly prepare the buffer. In addition, protease inhibitor cocktails (Roche) can be added because they do not interfere with the proteasome activity.

Urea buffer This buffer is $8 \mathrm{M}$ urea in $100 \mathrm{M}$ ammonium bicarbonate solution. Freshly prepare the buffer and keep it at room temperature before use.

Assay buffer Mix $50 \mathrm{mM}$ Tris- $\mathrm{HCl}$ (pH 7.5), $250 \mathrm{mM}$ sucrose, $5 \mathrm{mM} \mathrm{MgCl}_{2}$, $1 \mathrm{mM}$ DTT, $2 \mathrm{mM}$ ATP and $50 \mathrm{mM} \mathrm{KCl}$. Freshly prepare the buffer. PD buffer Mix $50 \mathrm{mM}$ Tris- $\mathrm{HCl}$ (pH 7.5) and $150 \mathrm{mM} \mathrm{NaCl}$. This buffer can be stored at $4{ }^{\circ} \mathrm{C}$ for several weeks.

PD wash buffer I Dissolve $4 \mathrm{M}$ urea in $50 \mathrm{mM} \mathrm{NH}_{4} \mathrm{HCO}_{3}$. This buffer should be freshly prepared.

PD wash buffer II Mix $50 \mathrm{mM}$ Tris- $\mathrm{HCl}$ (pH 7.5) and $10 \mathrm{mM} \mathrm{NaCl}$. This buffer can be stored at $4{ }^{\circ} \mathrm{C}$ for several weeks.
On-bead digestion buffer Mix $100 \mathrm{mM}$ Tris- $\mathrm{HCl}$ (pH 7.8), $100 \mathrm{mM} \mathrm{NaCl}$, $1 \mathrm{mM} \mathrm{CaCl}_{2}, 2 \%$ (vol/vol) ACN and $10 \mathrm{ng} \mu \mathrm{l}^{-1}$ trypsin. This buffer should be freshly prepared.

Active site elution solution Add $10 \mu \mathrm{M}$ biotin in a mixture of $5 \%(\mathrm{vol} / \mathrm{vol})$ formic acid, 25\% (vol/vol) ACN and 70\% (vol/vol) $\mathrm{H}_{2} \mathrm{O}$. This solution should be freshly prepared.

Sample buffer, $4 \times$ Mix $1 \mathrm{ml}$ of 20\% (wt/vol) SDS, $1 \mathrm{ml}$ of $0.625 \mathrm{M}$ Tris- $\mathrm{HCl}$, $\mathrm{pH} 6.8,2.1 \mathrm{ml}$ of $87 \%(\mathrm{vol} / \mathrm{vol}$ ) glycerol, $0.4 \mathrm{ml}$ of $\beta-\mathrm{ME}, 0.1 \mathrm{ml}$ of $10 \%(\mathrm{wt} / \mathrm{vol})$ $\mathrm{BPB}$ and $0.4 \mathrm{ml}$ of $\mathrm{H}_{2} \mathrm{O}$. This buffer can be stored at $-20^{\circ} \mathrm{C}$ for several months. Running buffer, $5 \times$ Mix $42.6 \mathrm{~g}$ of Tris, $214 \mathrm{~g}$ of glycine and $300 \mathrm{ml}$ of $10 \%(\mathrm{wt} / \mathrm{vol})$ SDS in 4 liters of $\mathrm{H}_{2} \mathrm{O}$; when the contents are well dissolved, add $\mathrm{H}_{2} \mathrm{O}$ up to a volume of 5 liters. This buffer can be stored for several weeks. In-gel digestion buffer Mix $10 \mathrm{mM} \mathrm{NH}_{4} \mathrm{HCO}_{3}(\mathrm{pH} 8), 5 \%$ (vol/vol) $\mathrm{ACN}$, $1 \mathrm{mM} \mathrm{CaCl}_{2}$ and $10 \mathrm{ng}^{-1} \mathrm{l}^{-1}$ trypsin. This buffer should be freshly prepared. Gel block extraction solution Gel block extraction solution is $\%$ (vol/vol) FA in $67 \%(\mathrm{vol} / \mathrm{vol}) \mathrm{ACN} / \mathrm{H}_{2} \mathrm{O}$. Freshly prepare the solution.

Stage tip solution A Stage tip solution A is $0.5 \%$ (vol/vol) FA in $\mathrm{H}_{2} \mathrm{O}$. Freshly prepare the solution.

Stage tip solution B Stage tip solution B is $0.5 \%$ ( $\mathrm{vol} / \mathrm{vol}$ ) FA in $80 \%$ (vol/ $/ \mathrm{vol}$ ) ACN $/ \mathrm{H}_{2} \mathrm{O}$. Freshly prepare the solution.

LC-MS sample solution Mix $95 \mathrm{ml}$ of $\mathrm{H}_{2} \mathrm{O}, 3 \mathrm{ml}$ of $\mathrm{ACN}$ and $0.1 \mathrm{ml}$ of FA. This solution can be stored at room temperature for several weeks.

PB 7.5 (phosphate buffer) Mix $2 \mathrm{ml}$ of $50 \mathrm{mM} \mathrm{Na}_{2} \mathrm{HPO}_{4}$ and $7 \mathrm{ml}$ of $50 \mathrm{mM}$ $\mathrm{NaH}_{2} \mathrm{PO}_{4}$. This buffer can be stored at room temperature for several weeks. [L] Light dimethyl labeling buffer $(100 \mu \mathrm{l})$

\begin{tabular}{llc}
\hline Composition & \multicolumn{1}{c}{ Stock } & Volume $(\boldsymbol{\mu l})$ \\
\hline $\mathrm{PB} 7.5$ & & 90 \\
$\mathrm{CH}_{2} \mathrm{O}$ & $4 \%(\mathrm{vol} / \mathrm{vol})$ & 5 \\
$\mathrm{NaBH}_{3} \mathrm{CN}$ & $0.6 \mathrm{M}$ & 5 \\
\hline
\end{tabular}

$\Delta$ CRITICAL Freshly prepare the buffer.

[M] Medium dimethyl labeling buffer $(100 \mu \mathrm{l})$

\begin{tabular}{lcc}
\hline Composition & \multicolumn{1}{c}{ Stock } & Volume $(\boldsymbol{\mu l})$ \\
\hline $\mathrm{PB} 7.5$ & & 90 \\
$\mathrm{CD}_{2} \mathrm{O}$ & $4 \%(\mathrm{vol} / \mathrm{vol})$ & 5 \\
$\mathrm{NaBH}_{3} \mathrm{CN}$ & $0.6 \mathrm{M}$ & 5 \\
\hline
\end{tabular}

$\Delta$ CRITICAL Freshly prepare the buffer.

$[\mathrm{H}]$ Heavy dimethyl labeling buffer $(100 \mu \mathrm{l})$

\begin{tabular}{lcc}
\hline Composition & \multicolumn{1}{c}{ Stock } & Volume $(\boldsymbol{\mu l})$ \\
\hline $\mathrm{PB} 7.5$ & & 90 \\
${ }^{13} \mathrm{CD}_{2} \mathrm{O}$ & $4 \%(\mathrm{vol} / \mathrm{vol})$ & 5 \\
$\mathrm{NaBD}_{3} \mathrm{CN}$ & $0.6 \mathrm{M}$ & 5 \\
\hline
\end{tabular}

$\Delta$ CRITICAL Freshly prepare the buffer.

Proteasome inhibitors Although we describe the use of bortezomib ester, this ABPP method is also compatible with other proteasome inhibitors. We use it in our laboratory as a screening technique to determine the activity, potency and subunit specificity of novel and potential proteasome inhibitors. Most compounds are soluble in DMSO, and we make 500× stock dilutions before adding it to the biological sample (like cell culture) in order to keep the DMSO concentration at $<1 \%$ of the sample.

\section{EQUIPMENT SETUP}

Typhoon settings We use the Typhoon 9400 scanner to scan the gel with fluorescent ABP-labeled proteins. The scanning setting for MVB003 (Probe 3) and MVB127 (Probe 2) is fluorescence Cy3/TAMRA, $600 \mathrm{PMT}$ at $50 \mu \mathrm{m}$ pixel resolution. The setting for LW124 (Probe 1) is fluorescence 
Cy2 (with Blue Laser), $600 \mathrm{PMT}$ and $50 \mu \mathrm{m}$ pixel resolution. ImageJ software is used for quantifying the intensity of the bands after subtracting the background. ChemDoc settings We used the GelDoc system for imaging western blots and the GS800 scanner for imaging Coomassie-stained SDS-PAGE gels. The Quantity One program was used to operate the imaging systems, and was subsequently used for quantifying the intensity of the bands and/or lanes. The setting for imaging the western blots is 'chemiluminescence.' Orbitrap settings The general mass spectrometer settings we used were as follows: an electrospray voltage of $1.5 \mathrm{kV}$ was applied to the emitter; there was no sheath and auxiliary gas flow; the ion transfer tube temperature was set to $150^{\circ} \mathrm{C}$; capillary voltage was set to $15 \mathrm{~V}$; and tube lens voltage was set to $150 \mathrm{~V}$. Internal mass calibration was performed with airborne protonated polydimethylcyclosiloxane $(\mathrm{m} / z=445.12002)$ and the plasticizer protonated dioctyl phthalate ions $(m / z=391.28429)$ was used as the lock mass ${ }^{41}$.
For shotgun proteomics analysis, $10 \mu \mathrm{l}$ of the sample was pressure-loaded on the trap column at a flow rate of $10 \mu 1 \mathrm{~min}^{-1}$ for $5 \mathrm{~min}$, followed by peptide separation with a gradient of $35 \mathrm{~min} 5-30 \%$ B, 15 min 30-60\% B and 5 min $100 \% \mathrm{~A}$ at a flow rate of $300 \mu \mathrm{min}^{-1}$ split to $250 \mathrm{nl} \mathrm{min}^{-1}$ by the LTQ divert valve. For each data-dependent cycle, one full MS scan $(300-2,000 \mathrm{~m} / \mathrm{z})$ acquired at high mass resolution $(60,000$ at $400 \mathrm{~m} / z$, automatic gain control (AGC) target $1 \times 10^{6}$, maximum injection time $1,000 \mathrm{~ms}$ ) in the Orbitrap was followed by $3 \mathrm{MS} / \mathrm{MS}$ fragmentations in the LTQ linear ion trap (AGC target $5 \times 10^{3}$, maximum injection time $120 \mathrm{~ms}$ ) from the three most abundant ions. The $\mathrm{MS}^{2}$ settings were as follows: collision gas pressure, $1.3 \mathrm{mT}$; normalized collision energy, 35\%; ion selection threshold, 500 counts; activation $q=0.25$; and activation time, $30 \mathrm{~ms}$. Fragmented precursor ions that were measured twice within $10 \mathrm{~s}$ were dynamically excluded for $60 \mathrm{~s}$, and ions with $z<2$ or unassigned were not analyzed ${ }^{17}$.

\section{PROCEDURE}

1| There are two options, depending on whether you want to perform high-resolution fluorescence ABPP on cell lysates (option A) or quantitative LC-MS-based ABPP (option B). For option A, we recommend using three different fluorescent probes for the ABPP: LW124 (1) to detect $\beta 1$ ( $\beta 1 i)$, MV127 (2) to detect $\beta 5$ ( $\beta 5 i)$ and MV003 (3) to detect all the subunits (Fig. 1) 17,18. This is done in order to get perfect separation between the constitutive and immunoproteasome subunits on SDS-PAGE for quantification purposes. For option B, to quantify proteasome in living cells, we recommend using $\mathrm{N}_{3}$-epoxomicin $(5)^{17,21}$ because it is cell permeable. We also suggest using biotin-phosphine $(6)^{22,23}$ for the bio-orthorgonal ligation to install the biotin tag; for in vitro experiments, biotin-epoxomicin (4)17 can be used directly (Fig. 1).

\section{(A) High-resolution fluorescence ABPP $\bigcirc$ TIMING $3 \mathrm{~d}$}

(i) Make $10 \mathrm{mM}$ stocks of all probes and inhibitors in DMSO and use DMSO as a negative control for your experiments.

(ii) Seed $2.5 \times 10^{6}$ MCF7 cells in 10-cm Petri dishes; culture the cells to $70-80 \%$ confluency and treat them with $0,20,50$ and $100 \mathrm{nM}$ bortezomib for $16 \mathrm{~h}$. From logarithmically growing AM01 cultures, use $10 \times 10^{6}$ cells and treat them with $0,10,20$ and $50 \mathrm{nM}$ bortezomib for $16 \mathrm{~h}$ (ref. 20).

! CAUTION The number of cells, concentration of bortezomib and time of treatment should be determined according to the sensitivity of the cells to the proteasome inhibitor.

(iii) Lyse the cells and determine the protein concentration as described in Box 1. Typical cell pellets of 10-20 $\mu$ are lysed in 40-80 $\mu \mathrm{l}$ of lysis buffer, and the protein concentration is in the range of $10-20 \mu \mathrm{g} \mu \mathrm{l}^{-1}$.

(iv) Prepare $20 \mu \mathrm{g}$ of total protein for each sample, and bring the total volume up to $9 \mu \mathrm{l}$ by adding assay buffer. Next, add $1 \mu \mathrm{l}$ of $10 \times$ working stock of the ABP, yielding final ABP concentrations of $0.5 \mu \mathrm{M}$ LW124 (1), $0.5 \mu \mathrm{M}$ MVB127 (2) or $2 \mu \mathrm{M}$ MVBO03 (3). Incubate the mixture at $37^{\circ} \mathrm{C}$ for $1 \mathrm{~h}$. Add $5 \mu \mathrm{l}$ of $3 \times$ sample buffer, and boil the sample for 5 min at $100^{\circ} \mathrm{C}$.

(v) We use the lanes with $0 \mathrm{nM}$ bortezomib as positive controls; as shown in Figure 2, we see clear proteasome inhibition by the treatment. If any other proteasome inhibitor is used in a similar experiment, as negative controls we suggest using deactivated lysate by boiling it with $1 \%$ (wt/vol) SDS or blocking the proteasome with $10 \mu \mathrm{M} \mathrm{N}$-epoxomicin (5) before incubation with the ABP. In these lanes, we expect no clear proteasome bands to appear.

(vi) Separate the proteins using $12.5 \%$ (wt/vol) SDS-PAGE.

(vii) Scan the gels on a typhoon scanner with correct settings (Equipment Setup).

(viii) As loading control, stain the gels with Coomassie, scan them on the Bio-Rad GS-800 scanner and determine the signal intensity for the total amount of protein in each lane using the QuantityOne program. Normalize all lanes to the highest intensity value to correct for pipetting errors.

(ix) Quantify the fluorescence image with ImageJ software by drawing a region of interest around individual bands; follow this by background subtraction before calculating the proteasome activity and correction for pipetting errors. The fluorescence gel image and the quantification graphs from MCF7 and AM01 are shown in Figure 2.

\section{(B) Quantitative LC-MS-based ABPP $\bigcirc$ TIMING $8 \mathrm{~d}$}

(i) Cell treatment. Treat $1 \times 10^{8}$ EL4 cells with the proteasome inhibitor bortezomib at the following concentrations: $0,10,100,1$ and $10 \mu \mathrm{M}$. DMSO can be used as negative control, and we keep the concentration of DMSO below $1 \%$ (vol/vol). After $2 \mathrm{~h}$ of incubation, add $10 \mu \mathrm{M} \mathrm{N}$-epoxomicin (5) to each sample, and incubate the cells again for $2 \mathrm{~h}$. Check the cells by light microscopy for signs of necrosis, shrinking, apoptosis or other toxicities. Lyse the cells as described in Box 1. 
(ii) $A B P$ reaction. For direct labeling, cell lysate (1-2 $\mathrm{mg}$ of protein in total) plus $10 \mu \mathrm{M}$ biotin-epoxomicin (4) is incubated at $37^{\circ} \mathrm{C}$ for $1 \mathrm{~h}$. For two-step labeling, add $250 \mu \mathrm{M}$ biotin-phosphine (6) to cell lysates from $\mathrm{N}_{3}$-epoxomicin (5)-treated living cells and incubate the mixture at $37^{\circ} \mathrm{C}$ for $1 \mathrm{~h}$. Empirically, we found that the two-step labeling of the proteasome in native (nondenatured) lysates with a high excess of biotin-phosphine (6) showed the best reaction and pull-down efficiency compared with the $\mathrm{Cu}(\mathrm{I})$-catalyzed Huisgen 1,3-dipolar cycloaddition (click chemistry) ${ }^{34}$ or the copper-free click $^{37}$.

! CAUTION Use lysis buffer to adjust the total volume to $180 \mu \mathrm{l}$.

(iii) Denaturation. Add $20 \mu \mathrm{l}$ of $10 \%$ (wt/vol) SDS to the reaction mixture, vortex it slightly and then boil it at $100{ }^{\circ} \mathrm{C}$ for $5 \mathrm{~min}$ for denaturation. Vortex the solution homogenously and centrifuge it for $5 \mathrm{~min}$ at 12,000 r.p.m. to pellet any aggregates. Transfer the clear supernatant into a new 2-ml low-binding Eppendorf tube.

(iv) Chloroform/methanol precipitation ${ }^{38}$. Add $800 \mu \mathrm{l}$ of methanol to the $200-\mu \mathrm{l}$ protein solution and vortex the tube vigorously.

(v) Add $200 \mu \mathrm{l}$ of chloroform and vortex the tube vigorously.

(vi) Add $600 \mu \mathrm{l}$ of $\mathrm{H}_{2} \mathrm{O}$ (to get phase separation), vortex the tube vigorously and centrifuge it (2 min at room temperature, $9,000 \mathrm{~g}$ ). We obtain a three-layer separation: an upper layer of water, a film of protein in the middle and a lower layer of chloroform.

(vii) Carefully remove and discard the upper layer.

(viii) Add $600 \mu \mathrm{l}$ of methanol, vortex the mixture at low speed, thoroughly, and centrifuge it (2 min at room temperature, 9,000g). ! CAUTION Avoid disrupting the protein membrane in too many small pieces because they will not sediment well during the next centrifugation step.

(ix) Carefully discard the supernatant by pipetting and air-dry the pellet for exactly 5 min in the flow air cabinet, with the tube upside down.

$\triangle$ CRITICAL STEP Both too-wet or too-dry pellets do not hydrate well. The protein pellet should be dried for exactly $5 \mathrm{~min}$. If it is drier or wetter, it will be hard to dissolve it in the buffer for further steps.

(x) Rehydrate the protein pellet in $180 \mu \mathrm{l}$ of urea buffer ( $8 \mathrm{M} \mathrm{urea} / 100 \mathrm{mM} \mathrm{NH}_{4} \mathrm{HCO}_{3}$ ) for $15 \mathrm{~min}$ at room temperature.

(xi) Reduction and alkylation (to disable cysteine bridge formation). Add $10 \mu \mathrm{l}$ of fresh $90 \mathrm{mM}$ DTT (in $8 \mathrm{M} \mathrm{urea/100} \mathrm{mM}$ $\mathrm{NH}_{4} \mathrm{HCO}_{3}$ ) to the $180-\mu \mathrm{l}$ sample and incubate this mixture for $30 \mathrm{~min}$ at $37^{\circ} \mathrm{C}$. Note that $1 \%(\mathrm{wt} / \mathrm{vol}) \mathrm{SDS}$ or the acid-labile surfactant RapiGest (Waters) can be used instead of $8 \mathrm{M}$ urea.

! CAUTION Temperatures $>37^{\circ} \mathrm{C}$ can cause carbamylation of proteins by urea.

(xii) Add $15 \mu \mathrm{l}$ of $200 \mathrm{mM}$ IAA (in $8 \mathrm{M}$ urea/100 mM NH${ }_{4} \mathrm{HCO}_{3}$ ) solution to the $190-\mu \mathrm{l}$ sample and incubate it for 30 min at room temperature in the dark.

! CAUTION The reaction is light sensitive.

(xiii) Centrifuge the tube for $5 \mathrm{~min}$ at top speed at room temperature, and transfer the supernatant to a new 2-ml Eppendorf tube.

(xiv) Chloroform/methanol precipitation. Repeat Step $1 \mathrm{~B}(\mathrm{iv}-\mathrm{ix})$. We advise performing this extra precipitation step in order to remove the excess free ABP or free tag in the case of the two-step labeling protocol.

(xv) Stepwise dilution of SDS. Add $25 \mu \mathrm{l}$ of $2 \%$ (wt/vol) SDS in PD buffer to the pellet and vortex the mixture to help dissolve the pellet. Dilute the SDS with normal PD buffer step by step. Heating the mixture to $70^{\circ} \mathrm{C}$ can also enhance protein solubility.

(xvi) Dilute the mixture three times with $25 \mu \mathrm{l}$ of PD buffer, vortex it after each addition of PD buffer and ensure that the solution becomes clear.

(xvii) Add the rest in nine $100-\mu$ l steps of PD buffer, to make the SDS final concentration $0.05 \%$ (wt/vol) and to obtain a clear solution.

! CAUTION Be patient during this step, as it may take a long time to homogenously disperse the entire pellet. However, we should dissolve it as much as possible. If necessary, use a heated water bath and/or sonic bath to help dissolve the pellet. It is important to avoid lumps of protein here because they will nonspecifically stick to the beads, yielding high background.

$\Delta$ CRITICAL STEP This is the hardest step in the whole protocol. This tiny volume might not be sufficient to solve your protein completely, but a larger amount is not possible as you might end up with a very high SDS concentration in the pull-down step and lose efficiency there. Disperse the protein in this volume by vortexing the tube vigorously. Do not pipette the mixture up and down because lumps of protein can stick in the tips and there is a potential for foam formation. The proteins will dissolve once the PD buffer is added stepwise. This increases the volume while keeping the concentration of SDS relatively high.

(xviii) Centrifuge at top speed for $5 \mathrm{~min}$ at room temperature and transfer the supernatant to a new 2-ml Eppendorf tube. $\triangle$ CRITICAL STEP After bringing the volume of the PD mixture to $1 \mathrm{ml}$ by adding PD buffer, centrifuge the mixture at top speed for $5 \mathrm{~min}$ at room temperature to remove all the insoluble particles. Otherwise, there might be nonspecific protein binding to the beads and an increase in background during analysis. 
Figure 4 | Direct and two-step activity-based affinity purification of the proteasome $\beta$-subunits with streptavidin beads from EL4 lysate.

(a-d) SDS-PAGE/silver stain analysis after treatment with biotin-epoxomicin (4) showing proteins eluted from the beads, input and supernatant; bands indicated by arrows were identified by LC-MS (1: propionyl-CoA carboxylase, 2: 60 S ribosomal protein, $3: \beta 2,4: \beta 2 i, 5: \beta 1,6: \beta 5 \beta 5 i \beta 1 i, 7:$ streptavidin) (a); western blot probed with streptavidin-HRP of the same samples from a (M, molecular marker) (b); SDS-PAGE/silver stain analysis after treatment with DMSO or $\mathrm{N}_{3}$-epoxomicin (5) and ligation with biotin-phosphine (6) showing proteins eluted from the beads $(\mathbf{c})$; western blot probed with streptavidin-HRP of the samples from $\mathbf{c}$ next to the input and supernatant samples (d).

(xix) Pull-down with paramagnetic beads. Add $50 \mu \mathrm{l}$ of streptavidin magnetic beads (prewashed with water, PD buffer and $0.05 \%$ (wt/vol) SDS PD buffer). Pull down for $1 \mathrm{~h}$ at room temperature with vigorous shaking.

(xx) Place the tubes with the pull-down sample on the DynaMag, wait for 3 min and pipette the supernatant into another tube.

(xxi) Run a sample of the supernatant on an SDS-PAGE gel to assess the pull-down efficiency (Fig. 4).

(xxii) Washing. Wash the beads as shown in the in-text table below, and then divide them: $2 / 3$ for in-gel detection and $1 / 3$ for on-bead digestion. Note that after the pull-down the beads might behave slightly differently in solution because their surface properties have been changed by the binding of the biotinylated proteins.

\begin{tabular}{ll}
\hline Once & PD buffer (containing $0.1 \%$ (wt/vol) SDS), $300 \mu \mathrm{l}$ \\
Twice & PD buffer, $300 \mu \mathrm{l}$ \\
Once & Wash buffer I, $300 \mu \mathrm{l}$ \\
Once & Wash buffer II, $300 \mu \mathrm{l}$ \\
Twice & Water, $300 \mu \mathrm{l}$ \\
\hline
\end{tabular}

(xxiii) In-gel detection. Elute the proteins from the beads with $100 \mu \mathrm{l}$ of $1 \times$ sample buffer containing $10 \mu \mathrm{M}$ biotin by boiling it for $5 \mathrm{~min}$ at $100^{\circ} \mathrm{C}$.

(xxiv) Put the samples on the DynaMag for $3 \mathrm{~min}$; transfer the supernatant to another tube while it is still warm.

$\triangle$ CRITICAL STEP Keep the boiled sample tubes on the DynaMag when you are loading the samples onto the gel in order to avoid loading the beads. If the beads are also loaded, the background can be increased.

(xxv) Resolve the samples on a $12.5 \%$ (wt/vol) SDS-PAGE gel and silver-stain the samples. After staining, scan the stained gel on the GS-800 scanner, excise the protein bands and perform in-gel digestion steps ${ }^{39}$. A typical silver-stained gel image of biotin-epoxomicin (4) pull-down in EL4 cells is shown in Figure 4a. Cut the desired gel bands into 1-mm ${ }^{3}$ blocks with a surgery knife, and keep them in a 1.5-ml Eppendorf tube.

$\triangle$ CRITICAL STEP In case Coomassie stain is used, destaining is necessary because the blue dye is not removed by stage tip desalting, and it is unwanted in the LC-MS system.

PAUSE POINT The gel blocks can be kept at $-20^{\circ} \mathrm{C}$ for a couple of weeks.

(xxvi) Wash the gel blocks with $100 \mu$ of Milli-Q water.

(xxvii) Discard the water and add $500 \mu \mathrm{l}$ of ACN to shrink the gel blocks, and then vortex the mixture slightly (the gel blocks will shrink, and become white and sticky).

(xxviii) Discard the ACN and dry the gel blocks for 5 min in the air flow.

(xxix) Swell the gel blocks with $25 \mu \mathrm{l}$ of in-gel digestion buffer on ice for at least $2 \mathrm{~h}$.

(xxx) Digest the blocks in a $37^{\circ} \mathrm{C}$ incubator (with shaker) overnight.

(xxxi) Add $100 \mu \mathrm{l}$ of gel-block extraction solution and incubate the mixture at $37^{\circ} \mathrm{C}$ for $15 \mathrm{~min}$.

(xxxii) Spin down and transfer the supernatant to new Eppendorf tubes; evaporate the ACN from the samples at $50{ }^{\circ} \mathrm{C}$ in a SpeedVac until the volume is $<30 \mu \mathrm{l}$. 
(xxxiii) Add $50 \mu \mathrm{l}$ of stage tip solution $\mathrm{A}$ to adjust the $\mathrm{pH}$ to $<5$.

! CAUTION The peptides should be desalted by using stage tips before LC-MS analysis.

(xxxiv) On-bead digestion. Add $100 \mu$ of on-bead digestion buffer to the beads and digest the proteins at $37{ }^{\circ} \mathrm{C}$ with shaking overnight.

(xxxv) Place the tubes on the DynaMag for 3 min and transfer the supernatants to new Eppendorf tubes; add $5 \mu$ l of FA to adjust the $\mathrm{pH}$ to $<4$ in order to inhibit trypsin.

! CAUTION The peptides should be desalted by using stage tips before LC-MS analysis.

(xxxvi) Eluting the active site peptides. After on-bead digestion, wash the beads with $100 \mu \mathrm{l}$ of water, incubate them with $100 \mu \mathrm{l}$ of active site elution solution for $30 \mathrm{~min}$ at $37^{\circ} \mathrm{C}$ to release the active site peptide from the beads, evaporate the ACN in SpeedVac and add $50 \mu \mathrm{l}$ of stage tip solution A. The active site peptides from the mouse proteasome obtained after tryptic digestion of EL4 cell lysates are shown in the in-text table below. The reaction mechanism and typical results for the active site identification are shown in Figure 5.

\begin{tabular}{ll}
\hline Mouse proteasome subunit & Active site peptide sequence after tryptic digest \\
\hline$\beta 1$ & TTIMAVQFNGGVVLGADSR \\
$\beta 2$ & TTIAGVVYK \\
$\beta 5$ & TTTLAFK \\
$\beta 1 \mathrm{i}$ & TTIMAVEFDGGVVVGSDSR \\
$\beta 2 \mathrm{i}$ & TTIAGLVFR \\
$\beta 5 \mathrm{i}$ & TTTLAFK \\
\hline
\end{tabular}

! CAUTION The peptides should be desalted using stage tips before LC-MS analysis.

$\triangle$ CRITICAL STEP All the tryptic-digested peptides should be desalted by using stage tips before they are loaded on the LC-MS for analysis. For the protein identification samples (such as in-gel digest and active site peptide identification samples), a single stage-tip desalting is enough for the LC-MS sample preparation, which is described in Step 1B(xxxvii). The samples that need to be quantified (for instance, the on-bead digest samples treated with different bortezomib concentrations) should be both dimethyl-labeled by stable isotopes and desalted on stage tips before LC-MS analysis: proceed directly to Step 1B(xl).
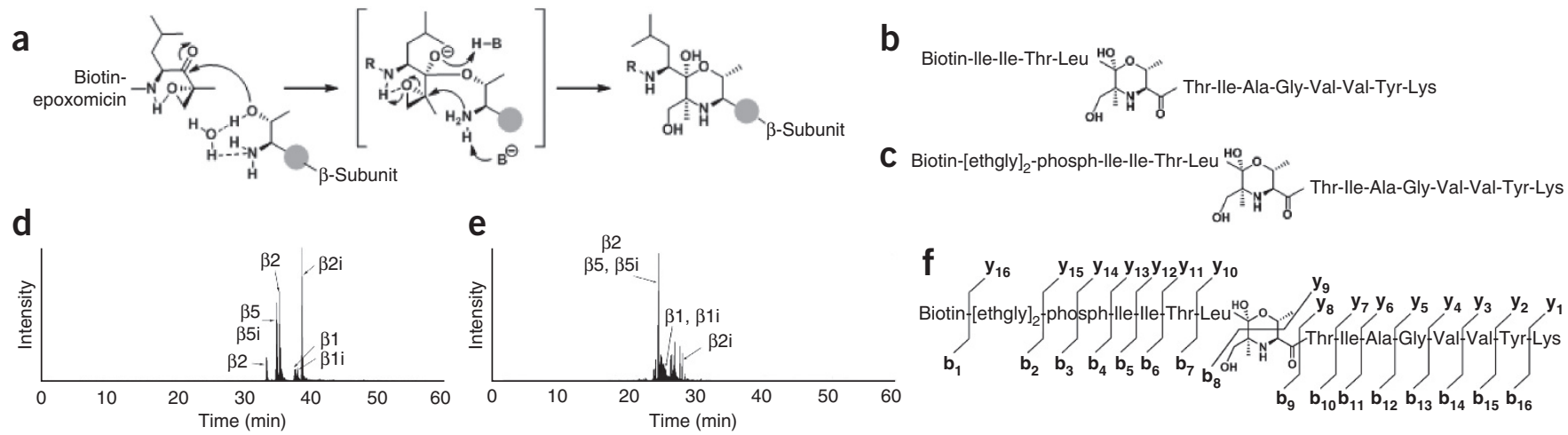

Figure 5 | Active site identification of the murine $\beta 2$ subunit by one-step and two-step ABPP with LC-MS analysis. (a) Reaction mechanism of biotin-epoxomicin (4) with the catalytic T1 residue. (b,c) Schematic representation of the direct [biotin-epoxomicin]-[ $\beta 2$ active site peptide] (b) and the two-step [biotinphosphine-epoxomicin] - [ $\beta 2$ active site peptide] (c) construct obtained after on-bead tryptic digestion. (d,e) LC-MS analysis and identification of the [biotin-epoxomicin]-[active site peptides] (d) and two-step [biotin-phosphineepoxomicin]-[active site peptides] (e) from constitutive proteasomes and immunoproteasomes. (f) Theoretical MS/MS fragmentation pattern for the two-step [biotin-phosphine-epoxomicin] - [ $\beta 2$ active site peptide] construct.

(g) experimental data for $\mathbf{f}$ showing the diagnostic ions b6, b7, b8, b3 and b4 after MS/MS fragmentation, and subsequently the MS $^{3}$ fragmentation of the $y 9$ ion revealing the amino acid sequence of the [ $\beta 2$ active site peptide] part of the construct.

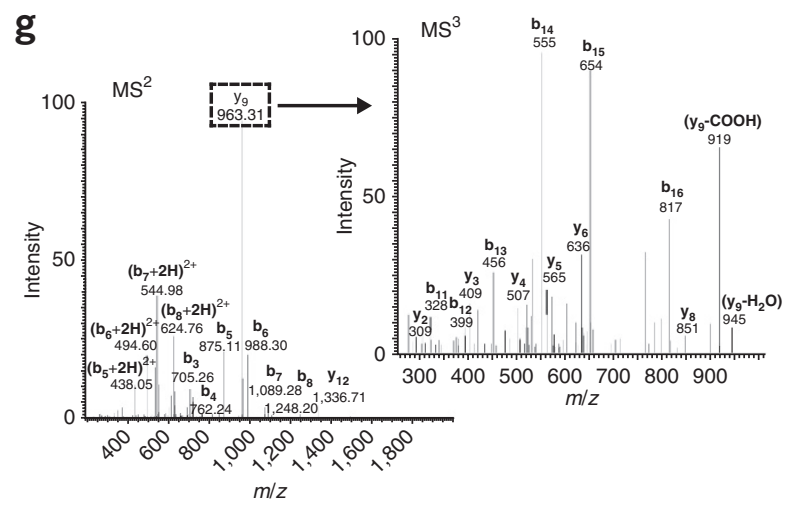


Figure 6 | Competitive ABPP assay in EL4 cells. Constitutive proteasome and immunoproteasome incubated with increasing bortezomib

concentrations for $2 \mathrm{~h}$, as well as residual $\beta$-subunit activity captured with $10 \mu \mathrm{M} \mathrm{N}$-epoxomicin (5) and biotin phosphine (6). (a) Qualitative analysis by SDS-PAGE and silver-stained gel after pull-down with streptavidin beads; (b) quantification of the $\beta$-subunit activity by on-bead tryptic digestion, dimethyl stable isotope labeling and LC-MS-based proteomics. a.u., arbitrary units. Error bars indicate results from three independent experiments.

(xxxvii) Desalting using stage tips. The stage tips we used
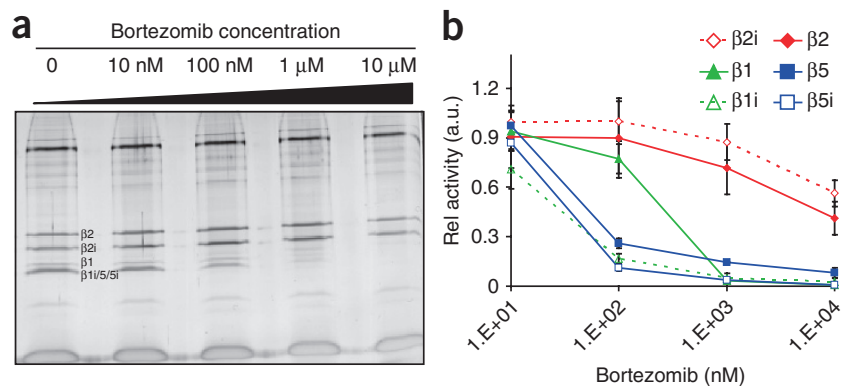
are made of $\mathrm{C} 18$ material inserted in $200-\mu$ l pipette tips ${ }^{40}$. Desalt the peptide samples as shown in the table below.

\begin{tabular}{ll}
\hline $\begin{array}{l}\text { Conditioning } \\
\text { Conditioning }\end{array}$ & Methanol, $50 \mu \mathrm{L}$ \\
Conditioning & Stage tip solution B, $50 \mu \mathrm{l}$ \\
Loading & Load samples on stage tips \\
Washing & Stage tip solution A, $100 \mu \mathrm{l}$ \\
Elution & Stage tip solution B, $100 \mu \mathrm{l}$ \\
\hline
\end{tabular}

I CAUTION Run the solutions through the stage tips by low-speed centrifugation (400-800 $\mathrm{g}$ for $2 \mathrm{~min}$ at room temperature).

(xxxviii) Evaporate the ACN from samples until the volume is $<20 \mu \mathrm{l}$.

(xxxix) Add $50 \mu$ l of LC-MS sample solution, and then the samples are ready for LC-MS analysis.

(xl) On-stage tip dimethyl labeling. Follow Step $1 \mathrm{~B}$ (xxxvii) until washing. After washing, load $20 \mu \mathrm{l}$ of $\mathrm{L}, \mathrm{M}$ or $\mathrm{H}$ reagents into each of the assigned stage tips.

(xli) Centrifuge the mixture at $100 \mathrm{~g}$ for $5 \mathrm{~min}$ in an Eppendorf centrifuge (adjust the speed such that $20 \mu \mathrm{l}$ of reagent flows through the stage tip in around $5 \mathrm{~min}$ ). Before this step, you can determine the optimal centrifuge speed by using a conditioned stage tip loaded with $20 \mu \mathrm{l}$ of PB 7.5.

(xlii) Repeat Step 1B(xli) four times.

$\triangle$ CRITICAL STEP It is important to keep the dimethyl labeling buffer on the stage tips for longer than 10 min, or there might be insufficient labeling.

(xliii) Wash the stage tips with $100 \mu$ l of stage tip solution A.

(xliv) Elute the peptides with $100 \mu$ of stage tip solution B.

(xlv) Mix the three samples 1:1:1 in a new Eppendorf tube, and then evaporate ACN in a SpeedVac at $50{ }^{\circ} \mathrm{C}$ until the volume is $<60 \mu \mathrm{l}$.

(xlvi) Add $100 \mu$ l of LC-MS sample solution and perform LC-MS analysis.

! CAUTION It is important to keep the solutions and reagents on ice in order to prevent degradation. The isotopic reagents are light sensitive; use brown tubes to store the solutions.

- PAUSE POINT The prepared LC-MS samples can be kept at $4^{\circ} \mathrm{C}$ for several days.

(xlvii) LC-MS analysis, Mascot search and MaxQuant processing. Extract peak file lists from the .raw data files of the ABPP quantification results by using the DTA supercharge module from MSQuant, and submit the peak file lists to automated peptide identification by the Mascot search engine using a false discovery rate of $1 \%$ and ion cutoff scores of $>25$. Alternatively, the MaxQuant software can be used for the relative quantification of the proteomics data. The competitive inhibition profiles of bortezomib were normalized compared with the negative control and are presented in Figure 6. For more of the search engines' details, please refer to refs. 24,26,27.

\section{TIMING}

Step 1A, high-resolution fluorescence ABPP (including Box 1): $3 \mathrm{~d}$

Step 1B, quantitative LC-MS-based ABPP: $8 \mathrm{~d}$

Step 1B(i) (including Box 1), protein extraction: $2 \mathrm{~d}$

Step $1 B$ (ii-xxii), affinity purification: $1 \mathrm{~d}$

Step $1 B(x x$ iii-xxxiii), in-gel digestion: $2 d$

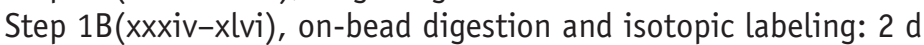

Step 1B(xlvii), LC-MS analysis and data processing: $1 \mathrm{~d}$ 


\section{ANTICIPATED RESULTS}

Figure 2 shows the results for a gel-based fluorescence ABPP quantification experiment in which the $\beta$-subunit activities were assayed after treatment of constitutive proteasome- and immunoproteasome-expressing cell lines with bortezomib. Proteins were resolved on a $12.5 \%$ (wt/vol) SDS-PAGE gel, and the separation between the $\beta 2$ and $\beta 2 i$ subunits is sufficient to use the pan-reactive probe MVB003 (3) to determine their activities. When only constitutive proteasome is present, MVB003 can also be used to quantify the closer-running $\beta 1$ and $\beta 5$ bands. However, in cells expressing both constitutive and immunoproteasomes, the resolution between the $\beta 1, \beta 1 i, \beta 5$ and $\beta 5 i$ is poor, and MVB003 cannot be used for reliable quantification. In this case, we use the subunit-specific probes LW124 (1) for $\beta 1 / \beta 1 i$ and MVB127 (2) for $\beta 5 / \beta 5 i$ separation and quantification. The results show that adherent MCF7 cells are less sensitive to bortezomib compared with the myeloma cell line AM01. Notably, bortezomib also lowers the $\beta 2 / \beta 2 i$ activity in AM01 cells, which is not observed in MCF7 cells. A possible explanation might be that the immunoproteasomes expressed by the AM01cells, but not by MCF7 cells, are more active and are thus more efficiently blocked by bortezomib. We consider this method to be a fast, robust and mediumthroughput (two to eight assays per day) screen for the proteasome activity that can be easily implemented in any biochemical laboratory.

Figure 5 shows a study for the active site identification of the mouse $\beta 2$-subunit using ABPP and LC-MS analysis. The epoxyketone electrophilic trap reacts with the catalytic Thr1 residue, yielding a stable morpholine ring. For a two-step ABPP protocol, biotin-phosphine (6) is then ligated to $\mathrm{N}_{3}$-epoxomicin (5), followed by affinity purification with streptavidin beads, on-bead tryptic digestion and elution of ABP-active site constructs. Figure $\mathbf{5 b}, \mathbf{c}$ shows the one-step and two-step constructs for the $\beta 2$-subunit, respectively. Figure $5 \mathbf{d}$,e shows chromatograms of the active-site constructs of all $\beta$-subunits after one-step and two-step ABPP, respectively. Figure $\mathbf{5} \mathbf{f}$ shows the theoretical fragmentation of the two-step ABP-active site construct of the $\beta 2$-subunit after collision-induced dissociation of the peptide bonds in $b$ and $y$ ions. Figure $5 \mathrm{~g}$ shows the experimental data of Figure $\mathbf{5 f}$. The $\mathbf{N}$ terminus of the molecule is labile and yields a typical fragmentation pattern of $b$ ions and the prominent appearance of the intact y 9 ion containing the peptide sequence originating from the $\beta 2$ protein. Subsequently, the y9 ion was isolated in the LTQ ion trap and subdued to a new round of fragmentation (MS3), thereby revealing the $\beta 2$ peptide sequence. Analysis of active site peptides is interesting from a toxicological perspective because covalent binding inhibitors might cause idiosyncratic drug-related toxicity. Expression of an epitope of the active site peptide attached to a xenobiotic compound on MHC class I molecules might induce an adverse immunological response and lead to allergy against the compound, which will exclude it from therapy. The method presented here can be used to determine epitope expression on MHC class I molecules.

The experiment shown in Figure 6 entails a competitive ABPP experiment between bortezomib and $\mathrm{N}_{3}$-epoxomicin (5) in living EL4 cells that express both constitutive proteasomes and immunoproteasomes. Cells were treated with $0,10,10^{2}$, $10^{3}$ and $10^{4} \mathrm{nM}$ bortezomib concentrations in parallel, and the residual proteasome activity was captured by two-step ABPP using the $\mathrm{N}_{3}$-epoxomicin/biotin-phosphine couple. Proteins were then affinity-purified with streptavidin beads and analyzed qualitatively by SDS-PAGE or subjected to on-bead trypsin digestion, and the resulting peptides were captured on stage tips. The first group contains peptides from the 0,10 and $10^{2} \mathrm{nM}$ bortezomib treatment, which were labeled light, medium and heavy, respectively, and which were eluted from stage tips, mixed 1:1:1 and analyzed by LC-MS. The second group contains peptides from the $0,10^{3}$ and $10^{4} \mathrm{nM}$ bortezomib treatment, which were labeled light, medium and heavy, respectively, and which were eluted, mixed 1:1:1 and analyzed by LC-MS. We used the $0 \mathrm{nM}$ bortezomib condition as a benchmark to combine the two groups, resulting in a quantification report on the proteasome activity. The relative quantitative analysis shows that bortezomib first hits the $\beta 1 \mathrm{i}-\beta 5$ - and $\beta 5 \mathrm{i}$-subunits and then the $\beta 1$ activity. At higher concentrations ( $>500 \mathrm{nM}$ ), the $\beta 2$ - and $\beta 2$-subunits are also inhibited. This method is suitable for quantitative determination of proteasome activity in living cells, and it is more accurate than the fluorescence gel-based method described previously because all active subunits are determined in the same LC-MS run.

Figure 4 is an illustration of the efficacy and robustness of the affinity purification protocol used for qualitative or quantitative determination of the proteasome activity. The results show typical pull-down efficiencies for one-step and two-step ABPP workflows, followed by streptavidin purification, SDS-PAGE separation of proteins and western blot analysis of biotinylated $\beta$-subunits visualized with streptavidin-horseradish peroxidase (HRP). This method is routinely used to determine pull-down efficiency.

ACKNOWLEDGMENTS We are grateful to the Netherlands Genomics Initiative, the Netherlands Proteomics Center and the Netherlands Organization for Scientific Research (NWO) for funding this work.

AUTHOR CONTRIBUTIONS N.L. carried out the cell culture (treatment), affinity purification, SDS-PAGE imaging work and prepared the first draft of the manuscript and subsequent modifications. C.-L.K. and G.P. carried out the cell culture (treatment), affinity purification and SDS-PAGE imaging work. M.V., L.I.W., W.A.v.d.L. and M.R. refined the design and synthesis of the chemical tools used in this work. H.v.d.E., E.v.G. and J.G. performed LC-MS analysis and data processing. G.P.v.W., H.S.O. and B.I.F. supervised the work and were involved in manuscript preparation.

COMPETING FINANCIAL INTERESTS The authors declare no competing financial interests.

Reprints and permissions information is available online at http://www.nature. com/reprints/index.html. 
1. Rock, K.L. \& Goldberg, A.L. Degradation of cell proteins and the generation of MHC class I-presented peptides. Annu. Rev. Immunol. 17, 739-779 (1999).

2. Kloetzel, P.M. \& Ossendorp, F. Proteasome and peptidase function in MHC-class-I-mediated antigen presentation. Curr. Opin. Immunol. 16, 76-81 (2004).

3. Kane, R.C., Bross, P.F., Farrell, A.T. \& Pazdur, R. Velcade: U.S. FDA approval for the treatment of multiple myeloma progressing on prior therapy. Oncologist 8, 508-513 (2003).

4. Jung, T., Catalgol, B. \& Grune, T. The proteasomal system. Mol. Aspects Med. 30, 191-296 (2009).

5. Marques, A.J., Palanimurugan, R., Matias, A.C., Ramos, P.C. \& Dohmen, R.J. Catalytic mechanism and assembly of the proteasome. Chem. Rev. 109, 1509-1536 (2009).

6. Borissenko, L. \& Groll, M. $20 \mathrm{~S}$ proteasome and its inhibitors: crystallographic knowledge for drug development. Chem. Rev. 107 687-717 (2007).

7. Murata, S. et al. Regulation of $\mathrm{CD}^{+} \mathrm{T}$ cell development by thymus-specific proteasomes. Science 316, 1349-1353 (2007).

8. Verdoes, M., Florea, B.I., van der Marel, G.A. \& Overkleeft, H.S. Chemical tools to study the proteasome. Eur. J. Org. Chem. 20, 3301-3313 (2009).

9. Kisselev, A.F. \& Goldberg, A.L. Monitoring activity and inhibition of $26 \mathrm{~S}$ proteasomes with fluorogenic peptide substrates. Methods Enzymol. 398, 364-378 (2005).

10. Li, N., Overkleeft, H.S. \& Florea, B.I. Activity-based protein profiling: an enabling technology in chemical biology research. Curr. Opin. Chem. Biol. 16, 227-233 (2012)

11. Fenteany, G. et al. Inhibition of proteasome activities and subunit-specific amino-terminal threonine modification by lactacystin. Science $\mathbf{2 6 8}$ 726-731 (1995).

12. Meng, L. et al. Epoxomicin, a potent and selective proteasome inhibitor, exhibits in vivo antiinflammatory activity. Proc. Natl. Acad. Sci. USA 96 10403-10411 (1999).

13. Bogyo, M. et al. Covalent modification of the active site threonine of proteasomal $\beta$-subunits and the Escherichia coli homolog HslV by a new class of inhibitors. Proc. Natl. Acad. Sci. USA 94, 6629-6634 (1997).

14. Kessler, B.M. et al. Extended peptide-based inhibitors efficiently target the proteasome and reveal overlapping specificities of the catalytic $\beta$-subunits. Chem. Biol. 8, 913-929 (2001).

15. Berkers, C.R. et al. Activity probe for in vivo profiling of the specificity of proteasome inhibitor bortezomib. Nat. Methods 2, 357-362 (2005).

16. Verdoes, M. et al. A fluorescent broad-spectrum proteasome inhibitor for labeling proteasomes in vitro and in vivo. Chem. Biol. 13, 1217-1226 (2006).

17. Florea, B.I. et al. Activity-based profiling reveals reactivity of the murine thymoproteasome-specific subunit beta5t. Chem. Biol. 17, 795-801 (2010).

18. Verdoes, M. et al. A panel of subunit-selective activity-based proteasome probes. Org. Biomol. Chem. 8, 2719-2727 (2010).

19. Kraus, M. et al. Activity patterns of proteasome subunits reflect bortezomib sensitivity of hematologic malignancies and are variable in primary human leukemia cells. Leukemia 21, 84-92 (2007).

20. Ruckrich, T. et al. Characterization of the ubiquitin-proteasome system in bortezomib-adapted cells. Leukemia 23, 1098-1105 (2009).

21. Saxon, E. \& Bertozzi, C. Cell surface engineering by a modified Staudinger reaction. Science 287, 2007-2017 (2000).
22. Ovaa, H. et al. Chemistry in living cells: detection of active proteasomes by a two-step labeling strategy. Angew. Chem. Int. Ed. 42, 3626-3629 (2003).

23. Willems, L.I. et al. Triple bioorthogonal ligation strategy for simultaneous labeling of multiple enzymatic activities. Angew. Chem. Int. Ed. 51, 4431-4434 (2012).

24. Boersema, P.J., Raijmakers, R., Lemeer, S., Mohammed, S. \& Heck, A.J. Multiplex peptide stable isotope dimethyl labeling for quantitative proteomics. Nat. Protoc. 4, 484-494 (2009).

25. Raijmakers, R. et al. Target profiling of a small library of phosphodiesterase 5 (PDE5) inhibitors using chemical proteomics. Chem.Med.Chem. 5, 1927-1936 (2010).

26. Cox, J. \& Mann, M. MaxQuant enables high peptide identification rates, individualized p.p.b.-range mass accuracies and proteome-wide protein quantification. Nat. Biotechnol. 26, 1367-1372 (2008).

27. Cox, J. et al. A practical guide to the MaxQuant computational platform for SILAC-based quantitative proteomics. Nat. Protoc. 4, 698-705 (2009).

28. Kisselev, A.F., Songyang, Z. \& Goldberg, A.L. Why does threonine, and not serine, function as the active site nucleophile in proteasomes? J. Biol. Chem. 275, 14831-14837 (2000).

29. Singh, J., Petter, R.C., Baillie, T.A. \& Whitty, A. The resurgence of covalent drugs. Nat. Rev. Drug Discov. 10, 307-317 (2011).

30. Muchamuel, T. et al. A selective inhibitor of the immunoproteasome subunit LMP7 blocks cytokine production and attenuates progression of experimental arthritis. Nat. Med. 15, 781-787 (2009).

31. Kallemeijn, W.W. et al. Novel activity-based probes for broad-spectrum profiling of retaining $\beta$-exoglucosidases in situ and in vivo. Angew. Chem. Int. Ed. 51, 12529-12533 (2012).

32. Chang, J.T. et al. Asymmetric proteasome segregation as a mechanism for unequal partitioning of the transcription factor T-bet during T lymphocyte division. Immunity 34, 492-504 (2011).

33. Adibekian, A. et al. Click-generated triazole ureas as ultrapotent in vivoactive serine hydrolase inhibitors. Nat. Chem. Biol. 7, 469-478 (2011).

34. Weerapana, E., Speers, A.E. \& Cravatt, B.F. Tandem orthogonal proteolysisactivity-based protein profiling (TOP-ABPP) - a general method for mapping sites of probe modification in proteomes. Nat. Protoc. 2, 1414-1425 (2007).

35. Lin, G. et al. Inhibitors selective for mycobacterial versus human proteasomes. Nature 461, 621-626 (2009).

36. Gu, C. et al. Proteasome activity profiling: a simple, robust and versatile method revealing subunit-selective inhibitors and cytoplasmic, defense-induced proteasome activities. Plant J. 62, 160-170 (2010)

37. van der Linden, W.A. et al. Two-step bioorthogonal activity-based proteasome profiling using copper-free click reagents: a comparative study. Bioorg. Med. Chem. 20, 662-666 (2012).

38. Wessel, D. \& Flugge, U.I. A method for the quantitative recovery of protein in dilute solution in the presence of detergents and lipids. Anal. Biochem. 138, 141-143 (1984).

39. Shevchenko, A., Tomas, H., Havlis, J., Olsen, J.V. \& Mann, M. In-gel digestion for mass spectrometric characterization of proteins and proteomes. Nat. Protoc. 1, 2856-2860 (2006).

40. Rappsilber, J., Mann, M. \& Ishihama, Y. Protocol for micro-purification, enrichment, pre-fractionation and storage of peptides for proteomics using StageTips. Nat. Protoc. 2, 1896-1906 (2007).

41. Olsen, J.V. et al. Parts per million mass accuracy on an Orbitrap mass spectrometer via lock mass injection into a C-trap. Mol. Cell Proteomics 4, 2010-2021 (2005). 